\title{
OS ASPECTOS LIMITANTES DA FORMAÇÃO ACADÊMICA E INTERVENÇÃO PROFISSIONAL DOS AGENTES SOCIAIS ATUANTES NO CAMPO DO LAZER NO CENTRO DE ARTES E ESPORTES UNIFICADOS (CEU) ${ }^{1}$
}

Recebido em: 24/02/2016
Aceito em: 28/11/2016

Marcela Gomez Alves da Silva
Evandro Antonio Corrêa
Universidade Estadual Paulista "Julio de Mesquita filho"- UNESP/IB/Rio Claro
Rio Claro - SP - Brasil

RESUMO: Este artigo objetivou identificar os aspectos da formação acadêmica e intervenção profissional dos agentes sociais ${ }^{2}$ que atuam no campo do lazer no Centro de Artes e Esportes Unificados (CEU). Participaram da pesquisa 11 agentes sociais atuantes no CEU e as falas produzidas pelos agentes sociais foram analisados conforme elementos da análise de conteúdo e discutidos à luz da literatura. Evidenciaram-se quatro pontos problemáticos: a) formação acadêmica; b) intervenção profissional; c) contexto e d) limitações. Concluiu-se que os agentes sociais necessitam de uma formação específica no campo do lazer, seja na formação inicial e continuada evidenciando as perspectivas histórico-crítica e educacional e que sejam capazes de questionar a realidade frente a uma intervenção inter/trans/multidisciplinar com a capacidade de transformação social.

PALAVRAS CHAVE: Atividades de Lazer. Políticas Públicas. Desenvolvimento de Pessoal.

\section{THE LIMITING ASPECTS OF ACADEMIC EDUCATION AND PROFESSIONAL INTERVENTION OF SOCIAL AGENTS IN LEISURE FIELD IN CENTRO DE ARTES E ESPORTES UNIFICADOS (CEU)}

ABSTRACT: This article aimed to identify aspects of academic and professional intervention of social agents involved in the field of leisure at the Centro de Artes e Esportes Unificados ( CEU ). The participants were 11 social agents working in the $\mathrm{CEU}$ and the lines produced by social agents were analyzed according to content

\footnotetext{
${ }^{1}$ Pesquisa financiada pela CAPES- Coordenação de Aperfeiçoamento de Pessoal de Nível Superior

${ }^{2}$ Agentes Sociais: refere-se às pessoas/profissionais que atuam nos programas e projetos de cunho social e educativo, que desenvolvem um trabalho comunitário, e têm por objetivo a interação social, a mobilização comunitária, incentivar ações comunitárias através da organização e mobilização local, a animação sociocultural, o agrupamento de atividades esportivas e de lazer e a educação popular (BRASIL, 2015; FREIRE, 1989).
} 
analysis of elements and discussed in light of literature. They showed up four problem areas : a) academic training; b ) professional intervention ; c ) environment and d ) limitations. It was concluded that social agents need specific training in the field of leisure, either in initial and continuing education highlighting the historical-critical perspective and education and are able to question the opposite reality to an intervention inter / trans / multidisciplinary with capacity for social transformation.

KEYWORDS : Leisure Activities. Public Policies. Staff Development.

\section{Introdução}

Conforme previsto no Art. $6^{\circ}$ da Constituição Federal são direitos do indivíduo “[...] a educação, a saúde, a alimentação, o trabalho, a moradia, o lazer, a segurança, a previdência social, a proteção à maternidade e à infância, a assistência aos desamparados" (BRASIL, 1988, itálico nosso). De forma que passa a ser dever da família, da sociedade e do Estado assegurar que tais direitos sejam contemplados.

Nesse sentido, a fim de promover estes direitos ou parte deles, o Governo Federal desenvolve ações de políticas públicas por meio de programas e projetos que são implementados nos municípios em parcerias com secretarias de Esporte e Lazer, Cultura e Bem-estar Social, entre outras, como, por exemplo, o Centro de Artes e Esportes Unificados (CEU).

O CEU é um programa do Governo Federal que tem o objetivo de integrar no mesmo espaço opções de lazer, ações culturais e qualificação profissional para o mercado de trabalho, serviços socioassistenciais, políticas de prevenção à violência e de inclusão digital, para promover a cidadania em territórios de alta vulnerabilidade social das cidades brasileiras (BRASIL, 2015).

Este programa visa, entre outros, a garantia de direitos quanto ao acesso de qualidade às políticas públicas de lazer e esporte, à socialização, o desenvolvimento integral das crianças e adolescentes e à promoção de cidadania em territórios de 
Marcela Gomez A. da Silva, Evandro Antonio Corrêa,Os Aspectos Limitantes da Formação Acadêmica... Dagmar Aparecida C. F. Hunger

vulnerabilidade social. Além da necessidade de construção de políticas que contribuam para a garantia da oferta de educação, de esporte e lazer como políticas e direitos de todos, com intuito de atender e possibilitar a participação e o protagonismo de um determinado público.

A partir destes objetivos e das opções oferecidas no programa deve-se considerar que a população atendida vivencie as diferentes atividades de lazer em seu "tempo livre” (DUMAZEDIER, 1979), sob a perspectiva criativa, emancipatória e educacional como as propostas de Marcellino (1987); Isayama (2003); Melo (2006).

Contudo, torna-se necessário que os profissionais que atuam ou que venham a atuar nesse local compreendam o lazer, seu aspecto educativo e suas possibilidades de acesso aos conteúdos culturais. Dumazedier (1980) define estes conteúdos como interesses culturais classificados em: artísticos, físico-esportivos, manuais, sociais, intelectuais; e, turístico (CAMARGO, 1982).

Esses conteúdos podem proporcionar vivências que contemplem e favoreçam a cultura lúdica do indivíduo, podendo se relacionar, interagir, se conhecer e se desenvolver pessoal e socialmente. Além de ter uma participação ativa dos indivíduos no processo de construção de seus valores e conhecimentos numa abordagem crítica e criativa como cidadão.

Sob esta ótica do lazer, torna-se relevante o papel do profissional (agentes sociais) que vai intervir nas diferentes instâncias como no CEU (foco deste estudo). Portanto, deve-se pensar na formação e atuação no campo do lazer e atentar-se para as armadilhas da “[...] comercialização de propostas de formação profissional na área", que Isayama (2010) menciona ocorrer na atualidade, como o "consumo exacerbado e alienado de bens materiais e de serviços "recreativos"”, contribuindo para uma "visão 
Marcela Gomez A. da Silva, Evandro Antonio Corrêa,Os Aspectos Limitantes da Formação Acadêmica... Dagmar Aparecida C. F. Hunger

reducionista do lazer" (ISAYAMA, 2010, p.18), de forma que devido às grandes possibilidades de ganhos e campos de atuação, muitos se interessam em atuar no campo do lazer sem formação específica.

Nesse interim, objetivou-se identificar os agentes sociais que atuam no programa "Centro de Artes e Esportes Unificado (CEU)", oferecido pelo Governo Federal no município de Bauru, evidenciando as características acadêmicas da sua formação no que diz respeito ao lazer e os aspectos limitantes da/para sua intervenção profissional.

Portanto, a formação e intervenção de agentes sociais que atuam no CEU, além do conhecimento específico de sua área, devem compreender o lazer e o seu duplo processo educativo (educação para e pelo o lazer) e suas possibilidades de vivência nos diferentes conteúdos do lazer, para que “[...] os envolvidos ampliem e descubram novas formas de ocupação do seu tempo fora do trabalho e das obrigações diversas" (MELO, 2008, p.14). Uma vez que o lazer pode valer-se “[...] como instrumento de mobilização política, de participação popular e de alcance da cidadania. No entanto, é relevante destacar que tais valores devem ser difundidos nas vivências de lazer, de modo espontâneo, prazeroso, alegre e divertido" (CLEMENTE; STOPPA, 2015, p. 253).

\section{Metodologia}

Tratou-se de um estudo qualitativo, o qual “[...] responde a questões muito particulares [...]" (MINAYO, 1994, p. 21) e "tem como objetivo traduzir e expressar o sentido dos fenômenos do mundo social [...]" (NEVES, 1996, s/n), na qual houve pesquisa de campo, definida por Lakatos e Marconi (2008, p.69) como: “[...] aquela utilizada com o objetivo de conseguir informações e/ou conhecimentos acerca de um problema para o qual se procura uma resposta, ou de uma hipótese que se queira comprovar". 
Marcela Gomez A. da Silva, Evandro Antonio Corrêa,Os Aspectos Limitantes da Formação Acadêmica... Dagmar Aparecida C. F. Hunger

Foram realizadas pesquisas bibliográficas (GIL, 1999) e analisados documentos tais como leis, regulamentos e pareceres, das secretarias do município e do programa selecionado para essa pesquisa, e conforme Lüdke e André (1986), a análise documental se trata de uma técnica que busca identificar informações nos documentos a partir de questões ou hipóteses de interesse.

Como técnica de coleta de dados, foi utilizada a entrevista semiestruturada, individualmente, com um roteiro prévio de 25 questões abertas. As entrevistas foram realizadas com onze agentes sociais que ministravam as oficinas oferecidas pelo programa no momento da pesquisa. Tratou-se de um estudo de caso delimitado por um grupo representativo a fim de compreender determinada situação, reunindo informações para análise sobre um campo específico “[...] objetivando tomar decisões a seu respeito ou propor uma ação transformadora" (CHIZZOTTI, 2008, p. 102).

Os sujeitos da pesquisa assinaram a um Termo de Consentimento Livre e Esclarecido aprovado pelo Comitê de Ética em Pesquisa conforme parecer 1.311.902. As entrevistas foram registradas por meio de gravação de áudio, com o objetivo de "[...] colher dados relevantes de determinadas fontes ou pessoas, em contato direto do pesquisador com sujeitos da amostra" (MATTOS, 2004, p.37).

As evidências resultantes das coletas foram tratadas a partir de elementos da técnica de análise de conteúdo proposta por Bardin (2011), em que foi realizado processo de categorização dos depoimentos. Os dados foram, posteriormente, confrontados com a bibliografia pertinente para análise.

Evidenciaram-se quatro categorias (eixos de discussão) e subcategorias de análise provenientes dos depoimentos orais da entrevista semiestruturada: a) formação (Formação Inicial; Formação acadêmica no campo do lazer; Formação continuada); b) 
Marcela Gomez A. da Silva, Evandro Antonio Corrêa,Os Aspectos Limitantes da Formação Acadêmica... Dagmar Aparecida C. F. Hunger

intervenção profissional; c) contexto (Relação sujeito-lazer; Relação sujeito- programa) e d) limitações encontradas da/para atuação.

\section{Direito Social ao Lazer}

Apesar do debate sobre as origens do lazer, optou-se nesse momento por seu momento histórico enquanto reinvindicações sociais a partir do século XVIII. Como fruto de reivindicações sociais, o lazer surge após a Revolução Industrial e passa a ser visto como direito social, onde ganhou importância nos setores públicos, pois a busca por uma menor jornada de trabalho, por um "tempo de folga" fez com que o lazer ganhasse maior importância para a manutenção da qualidade de vida. "O lazer surge assim mais do que uma necessidade, mais do que uma reivindicação, ele se torna um direito da pessoa humana, que passa a vivenciá-lo como um valor" (ROLIM, 1989, p. 56).

Marcellino (1983) chama atenção para as características assistencialistas do lazer, quando inserido no contexto das camadas populares, dessa forma, é necessário que as barreiras sociais e culturais sejam superadas, não restringindo a prática do lazer a uma classe que já acumula privilégios, os valores existentes nas atividades de lazer devem ser democratizados.

Para Pinto (2008) a partir do reconhecimento legal do lazer como direito social, nos anos 1990, deve-se compreendê-lo como um dos fatores que contribuem para o desenvolvimento social e humano, de forma que deve ser tratado no conjunto de medidas políticas necessárias à melhoria da qualidade de vida de todos. A autora esclarece que apesar de ter aumentado o acesso as atividades e aos espaços de lazer, ressalta que as políticas públicas favorecem a elite. Visto que o lazer funciona de forma 
Marcela Gomez A. da Silva, Evandro Antonio Corrêa,Os Aspectos Limitantes da Formação Acadêmica... Dagmar Aparecida C. F. Hunger

assistencialista para as camadas desfavorecidas da população e que a influência da indústria cultural faz com que o tempo de lazer sirva como tempo de consumo, incentivando o capitalismo e aumentando as desigualdades sociais no que diz respeito ao consumo de mercadorias lúdicas (PINTO, 2008).

Todavia, a garantia do direito ao lazer não deve se resumir à quantidade de tempo livre, mas sim à qualidade desse tempo. Tal direito está relacionado ao desenvolvimento humano, de forma que ao garantir o direito ao lazer, outros direitos são efetivados, como os relacionados à cultura e à educação, por exemplo (LUNARDI, 2015).

Pinto (2008, p. 90) ressalta o fato de que embora haja essa "[...] garantia de direitos ao lazer", ainda há “[...] uma distância significativa entre a institucionalização dos direitos sociais expressos nas políticas públicas implementadas e as condições reais de conquistas dos direitos dos sujeitos". Ainda há um déficit na consciência dos indivíduos para a garantia de seus direitos, de forma que a falta de estrutura, a falta de gestão e a execução de políticas de lazer não são reivindicadas por parte da população pelo desconhecimento do lazer enquanto direito.

Embora percebam que o lazer é importante, a população sente "vergonha" em relatar a prioridade que dão ao tempo de não trabalho, especificamente, o lazer. Pois como Marcellino (2008) pontua isso é visto como "coisa de vagabundo". Assim, o lazer passa a ser associado a "temas sérios", como por exemplo, "tirar as crianças da rua" (MARCELLINO, 2008, p.25).

Nesse interim, o maior desafio pontado por Pinto (2008) seria o desenvolvimento de políticas participativas segundo as quais o direito ao lazer deveria ser algo construído diariamente, o qual requer um "novo" olhar, consciência, ética dos 
Marcela Gomez A. da Silva, Evandro Antonio Corrêa,Os Aspectos Limitantes da Formação Acadêmica... Dagmar Aparecida C. F. Hunger

envolvidos, além da transparência e coerência dos fins e meios de implementação política, de seus pressupostos, diretrizes e formas de gestão e da avaliação da eficiência e efetividade social das ações realizadas.

Da mesma maneira, Marcellino (2008); Isayama (2003); Pinto (2008) e Werneck (1998) defendem que as políticas de lazer devem estar interligadas às políticas trabalhistas, reduzindo a jornada de trabalho, aos projetos urbanos, bem como a formação de profissionais da área. Além disso, o lazer “[...] não pode ser tratado de forma isolada de outras questões sociais" (MARCELLINO, 2008, p. 26).

Nesse sentido, políticas públicas de lazer e esporte devem ser pensadas, no município, de forma que integrem as secretarias municipais, bem como profissionais que dominem pelo menos um dos conteúdos do lazer e sua fundamentação teórica (ISAYAMA, 2003). Não se precisa, como menciona Marcellino (2001, 2008), de "bobos da corte", que pregam o divertimento na intenção de "desviar a atenção de".

O lazer abre múltiplas possibilidades. É preciso ações que se contraponham às da indústria cultural, na maioria das vezes exploradora do lazer mercadoria, do entretenimento na sua pior conotação. Uma política setorial de lazer, nos moldes aqui propostos, leva em conta as limitações estruturais, mas crê na especificidade da ação no plano cultural como um dos instrumentos de mudança (MARCELLINO, 2008, p. 34).

Os "bobos da corte" podem ser encontrados em muitos locais, inclusive atuando nos projetos e programas de cunho social, nas camadas vulneráveis da população, onde oferecem "divertimento" e uma "ocupação do tempo livre" que acabam por tentar "mascarar" as mazelas da sociedade, desviar a atenção dos problemas que a comunidade se insere, ou seja, uma visão próxima da política do "pão e circo". Contudo, Melo (2008, p. 14) ressalta que os projetos de cunho social devem perspectivar duas naturezas de intervenção: "a educação pelo tempo livre e a educação para o tempo livre". 
Marcela Gomez A. da Silva, Evandro Antonio Corrêa,Os Aspectos Limitantes da Formação Acadêmica... Dagmar Aparecida C. F. Hunger

Mediante uma educação para e pelo lazer torna-se relevante aos agentes sociais compreenderem as suas funções e de que forma podem intervir nas diferentes atividades propostas no CEU, que possuem relação com os interesses do lazer, e que podem, por meios deste, serem alcançados de maneira mais prazerosa, superando a "mesmice", colaborando com o desenvolvimento pessoal e social, divertimento e descanso dos envolvidos (MARCELLINO, 2008). Portanto, tendo em vista a formação e as possíveis dificuldades dos agentes sociais em atuar em programas de cunho sócio-educativos apresentam-se os resultados e análise obtidos a partir das entrevistas, conforme evidenciado no (QUADRO 1).

Quadro 1: Categorias e subcategorias de análise

\begin{tabular}{|l|l|l|}
\hline \multicolumn{1}{|c|}{ CATEGORIA } & SUBCATEGORIA & ELEMENTOS DE ANÁLISE \\
\hline \multirow{2}{*}{ FORMAÇÃO } & Formação Inicial & $\begin{array}{l}\text { Formação acadêmica no ensino } \\
\text { superior ou cursos técnicos }\end{array}$ \\
\cline { 2 - 3 } & $\begin{array}{l}\text { Formação acadêmica no campo } \\
\text { do lazer }\end{array}$ & $\begin{array}{l}\text { Vivência em disciplinas ou } \\
\text { atividades no campo do lazer } \\
\text { durante formação inicial. }\end{array}$ \\
\cline { 2 - 3 } & Formação continuada & $\begin{array}{l}\text { Cursos de pós-graduação, } \\
\text { especializaços e participação } \\
\text { em eventos da área. }\end{array}$ \\
\hline \multirow{2}{*}{ INTERVENÇÃO } & Intervenção profissional & $\begin{array}{l}\text { Tempo, locais e forma de } \\
\text { intervir. }\end{array}$ \\
\hline \multirow{2}{*}{ CONTEXTO } & Relação sujeito-lazer & $\begin{array}{l}\text { Conhecimentos e vivências no } \\
\text { campo do lazer }\end{array}$ \\
\cline { 2 - 3 } & Relação sujeito- programa & $\begin{array}{l}\text { Conhecimento do programa } \\
\text { envolvido, seus objetivos, } \\
\text { impactos e limitações. }\end{array}$ \\
\hline \multirow{2}{*}{ LIMITAÇÕES } & $\begin{array}{l}\text { Dificuldades encontradas na } \\
\text { atuação que de alguma forma } \\
\text { limitavam a prática profissional } \\
\text { de maneira geral e no campo do } \\
\text { lazer }\end{array}$ \\
\hline
\end{tabular}

O Quadro acima foi elaborado visando direcionar as evidências resultantes dos depoimentos orais dos agentes sociais, contribuindo para a análise a fim de estabelecer relações com o objetivo da pesquisa. 
Marcela Gomez A. da Silva, Evandro Antonio Corrêa,Os Aspectos Limitantes da Formação Acadêmica... Dagmar Aparecida C. F. Hunger

\section{Formação e Atuação no Lazer}

O lazer é um campo multidisciplinar, e dessa forma abrange profissionais de diferentes formações (Educação Física, Turismo etc.). Isayama (2003) explicita que a função do profissional de lazer não se restringe em formular brincadeiras, jogos ou animar festas, pois é um trabalho que requer fundamentos técnicos, pedagógicos, político-culturais e sociais. Já que para Marcellino (2005), o direcionamento excessivo das atividades, que deixa de lado o papel pedagógico da animação, contribui para reforçar os valores da ideologia dominante.

O profissional do lazer teria um papel relevante no processo de construção e ampliação dos canais de informação das pessoas, as possibilidades de Educação e de desenvolvimento pessoal e social por meio das vivências de lazer. Entretanto, é importante a formação de um profissional que tenha conhecimento do lazer e de suas vivências lúdicas, para assim compreender a diversidade cultural, buscando a reflexão e a ampliação do potencial crítico e criativo das pessoas envolvidas (ISAYAMA, 2003).

Sobre isso, Marcellino (2008) defende que para que o trabalho seja levado a sério, é preciso levar em conta o que Dumazedier chamou de "estrutura de animação", de "forma piramidal", tendo em seus vértices, animadores de competência geral, no meio da estrutura, animadores profissionais de competência específica e em sua base, animadores voluntários capacitados.

Seja qual for o vértice, surge a necessidade de profissionais que atuem no âmbito do lazer, campo este que vem crescendo substancialmente nas últimas décadas, principalmente, sob a visão do consumo. Cada vez mais se observa a procura por atividades que "fujam" da rotina e que distraiam as pessoas. O aumento pela procura desses profissionais não foi acompanhado pela formação e qualificação dos mesmos. De 
Marcela Gomez A. da Silva, Evandro Antonio Corrêa,Os Aspectos Limitantes da Formação Acadêmica... Dagmar Aparecida C. F. Hunger

forma que a formação se torna incompleta e, muitas vezes, direcionada ao consumo de bens culturais e de lazer, e pior, acaba por não agregar o crescimento e desenvolvimento dos indivíduos envolvidos (ISAYAMA, 2003).

Nesse sentido, os profissionais que atuam no campo do lazer, devem ter conhecimento multidisciplinar e entender o lazer como um meio de desenvolvimento de valores, atitudes. Devem atuar como educadores. Enxergar o componente educativo do lazer e a possibilidade de transformação da realidade social por meio dele, promotor de relações humanas.

Além das disciplinas ligadas ao lazer, o profissional deve se qualificar, refletir sobre sua própria prática. Utilizando-se da delimitação dos interesses do lazer: manuais, artísticos, físico-esportivos, intelectuais, sociais e turísticos. Assim, o profissional deve ter contato com todos esses conteúdos para poder intervir de maneira que se possa oferecer aos indivíduos vivências nos diferentes interesses culturais do lazer

Da mesma forma, Gomes (2011) destaca que o profissional

[...] que busca qualificar-se para o campo do lazer é um elemento chave na organização das situações de aprendizagem, pois se compromete com o desenvolvimento do lazer como uma ferramenta de educação social. Afinal, o lazer é um campo através do qual podemos refletir sobre a sociedade com seus grupos, suas formas de organização temporal/espacial, sua sociabilidade e seus conflitos (p. 43).

Segundo Isayama (2010), a formação no campo do lazer no Brasil possui duas perspectivas: a primeira mais técnica, onde surgem os problemas entre teoria e prática, o que restringe o profissional, tal formação tem como prioridade o “[...] domínio de procedimentos e metodologias" (ISAYAMA, 2010, p. 12). A segunda perspectiva é aquela "centrada no conhecimento, na cultura e na crítica" (p. 12), onde os 
Marcela Gomez A. da Silva, Evandro Antonio Corrêa,Os Aspectos Limitantes da Formação Acadêmica... Dagmar Aparecida C. F. Hunger

conhecimentos, os saberes e os valores são prioridades. Aqui se tem a preocupação na educação para e pelo lazer, o profissional possui papel social.

Assim, “[...] a formação de profissionais no campo do lazer deve, portanto, ser pautada na competência técnica, científica, política, filosófica e pedagógica e no conhecimento crítico da realidade" (ISAYAMA, 2010, p. 13). Nessa ótica de formação, os "profissionais de lazer devem ser educadores, no sentido amplo da palavra, e não mercadores, como habitualmente vem ocorrendo" (MARCELLINO, 2008, p. 40).

Dessa forma, questiona-se se os cursos de formação que possuem em seu currículo uma disciplina sobre o lazer, e além disso, se conseguem formar profissionais para atuar no âmbito do lazer. Portanto, Isayama (2010, p.21) enfatiza que a formação para atuar no campo do lazer deve oferecer elementos que consolide um profissional “crítico, criativo, questionador, reflexivo, articulador, pesquisador, interdisciplinar" que saiba de forma efetiva praticar suas "teorias".

Com esses e outros elementos pode ocorrer a intervenção dos agentes sociais num contexto de educação não formal. Tais ações se dão fora das escolas, em locais informais, locais, como menciona Gohn (2010, p. 19), onde "há processos interativos intencionais". A autora se refere à "Intencionalidade na ação" no sentido dos indivíduos participarem por livre escolha, aprender, transmitir e trocar saberes, buscando uma forma de educar que parta dos interesses e das necessidades dos envolvidos, contribuindo para que sejam abertas "janelas de conhecimento sobre o mundo".

Justifica-se assim a atuação de agentes sociais em programas destinados à socialização e ao desenvolvimento de crianças e adolescentes. Nesse sentido, Gohn (2010) apresenta alguns objetivos a serem alcançados pela educação não formal, os quais podem ser mais bem alcançados quando vinculados aos conteúdos culturais do 
Marcela Gomez A. da Silva, Evandro Antonio Corrêa,Os Aspectos Limitantes da Formação Acadêmica... Dagmar Aparecida C. F. Hunger

lazer e ao contexto de vida dos indivíduos inseridos nesses programas por meio da atuação desses agentes, resgatando o sentimento de valorização de si próprio; adquirindo conhecimentos a partir de sua própria prática e desenvolvendo a cultura política de grupo (GOHN, 2010, p. 21).

Partindo dos estudos realizados, houve, por meio das entrevistas, a possibilidade de compreender e relacionar o conteúdo estudado com a realidade dos agentes sociais. Portanto, a partir desses apontamentos apresenta-se a seguir os dados e a análise sobre o processo de formação, a atuação profissional, o contexto e limitações encontradas para atuar no campo do lazer, evidenciadas conforme relatos dos entrevistados.

\section{Formação dos Agentes Sociais}

\section{Formação Inicial e Continuada}

Nessa subcategoria demonstra-se no Quadro 2 a relação dos agentes sociais e sua formação inicial e continuada:

Quadro 2: Formação inicial e continuada

\begin{tabular}{|c|c|c|}
\hline $\begin{array}{l}\text { AGENTE } \\
\text { SOCIAL }\end{array}$ & FORMAÇÃO INICIAL & FORMAÇÃO CONTINUADA \\
\hline 1 & GRADUANDO EM EDUCAÇÃO FISICA & $\mathrm{NÃO}$ \\
\hline 2 & $\begin{array}{l}\text { GRADUADO EM LETRAS/GRADUANDO EM } \\
\text { EDUCAÇÃO MUSICAL }\end{array}$ & NÃO \\
\hline 3 & GRADUANDO EM EDUCAÇÃO MUSICAL & $\mathrm{NÃO}$ \\
\hline 4 & $\begin{array}{l}\text { GRADUADO EM LICENCIATURA PLENA EM } \\
\text { EDUCAÇÃO FÍSICA }\end{array}$ & TÉCNICO DESPORTIVO \\
\hline 5 & $\begin{array}{l}\text { GRADUADO EM PEDAGOGIA/GRADUANDO } \\
\text { EM EDUCAÇÃO MUSICAL }\end{array}$ & $\mathrm{NÃO}$ \\
\hline 6 & $\begin{array}{l}\text { GRADUADO EM LICENCIATURA EDUCAÇÃO } \\
\text { FÍSICA }\end{array}$ & GRUPOS DE ESTUDOS \\
\hline 7 & GRADUADO EM ARTES VISUAIS & NÃO \\
\hline 8 & $\begin{array}{l}\text { GRADUADO EM LICENCIATURA PLENA } \\
\text { EDUCAÇÃO FÍSICA }\end{array}$ & $\begin{array}{c}\text { ESPECIALIZAÇÃO EM } \\
\text { PSICOPEDAGOGIA E GRUPOS } \\
\text { DE ESTUDOS }\end{array}$ \\
\hline 9 & GRADUADO EM ARTES CÊNICAS & NÃO \\
\hline 10 & GRADUAÇÃO EM LICENCIATURA EM MÚSICA & $\mathrm{NA \tilde {O }}$ \\
\hline 11 & $\begin{array}{l}\text { GRADUADO EM BACHARELADO EM } \\
\text { EDUCAÇÃO FÍSICA }\end{array}$ & $\begin{array}{c}\text { ESPECIALIZAÇÃO EM } \\
\text { FISIOLOGIA DO EXERCÍCIO }\end{array}$ \\
\hline
\end{tabular}


Marcela Gomez A. da Silva, Evandro Antonio Corrêa,Os Aspectos Limitantes da Formação Acadêmica... Dagmar Aparecida C. F. Hunger

Observa-se no Quadro 2 que os sujeitos da pesquisa possuem formação em diferentes áreas, porém são áreas que contemplam de alguma forma, direta ou indireta, os interesses do lazer, sejam artísticos, manuais, intelectuais, físico-esportivos, sociais e turísticos. Possibilitando, talvez, no campo de atuação uma visão mais ampla, devido às diferentes formações acadêmicas e as vivências dos agentes sociais, o que contribui de maneira significativa para a ampliação do contato com diversas formas de conhecimento, bem como o desenvolvimento pessoal e social dos indivíduos envolvidos.

\section{Formação Acadêmica no Campo do Lazer}

Evidenciou-se aqui se houve ou há alguma disciplina ou atividade nos cursos realizados pelos agentes sociais que aborde/abordasse o conteúdo do lazer.

Conforme relato dos agentes sociais já graduados, as disciplinas que tratam sobre lazer faziam parte da grade curricular dos cursos de forma direta (disciplina específica) ou indireta (disciplina que abordava o assunto em alguns momentos), e conforme relatado por 2 agentes sociais que já haviam concluído há pelo menos 20 anos o curso de Educação Física, tal disciplina não existia na grade do curso. Também foi relatado que de alguma forma, nos cursos há 10 anos, o conteúdo do lazer era encontrado em quase todas as disciplinas práticas voltadas à iniciação esportiva, por meio de brincadeiras, por exemplo, e o conceito teórico do lazer, em sua maioria, era pouco abordado. Assim, os agentes consideravam o conteúdo insuficiente, de maneira geral. Os demais cursos de graduação abrangiam o conteúdo de forma indireta. Os agentes que ainda estavam no processo de graduação relataram ter conhecimento de que havia tal disciplina, mas não haviam sido ministradas por enquanto. 
Marcela Gomez A. da Silva, Evandro Antonio Corrêa,Os Aspectos Limitantes da Formação Acadêmica... Dagmar Aparecida C. F. Hunger

Nesse sentido, questionou-se os agentes sociais sobre a necessidade de uma disciplina que abordasse tal conteúdo, e todos os entrevistados consideravam importante a inserção de uma disciplina que abrangesse o conteúdo do lazer em seu curso de graduação, conforme destacado: "Sim, com certeza, acho que é importante para questionar vários fatores dentro da cultura $[\ldots]$ ter uma disciplina que abrange lazer e cultura no sentido de fomento sócio cognitivo, é superinteressante" (Agente social 7). “Sim, com toda certeza, pois trabalhamos com crianças [...] não é necessário, é primordial [...]" (Agente Social 5).

Sobre participação em eventos da área, percebeu-se que há interesse e procura por parte dos agentes sociais, porém encontram-se barreiras financeiras para a realização. Apesar dessa barreira, Isayama (2010) coloca que o animador cultural, os agentes sociais devem deter conhecimentos sobre os interesses do lazer, pelo menos o qual a pessoa trabalha de forma mais direta. Essa falta de conhecimento por parte dos profissionais se estende às pessoas que participam das atividades, pois as mesmas são limitadas pela falta de conhecimentos dos interesses que cercam o lazer e de suas mais variadas possibilidades, pois evidenciou-se que há uma necessidade de se educar para e pelo lazer não só os indivíduos envolvidos, mas sim os agentes sociais do programa.

Propõe-se que se aborde junto aos agentes sociais a proposta pedagógica inserida por Melo (2006), a animação cultural, que consiste numa formação e intervenção pedagógica que pode ser aplicada em diferentes contextos e espaços sociais. Atuando como mediador, o profissional possibilita e facilita a obtenção de conhecimento estimulando a percepção dos indivíduos, buscando uma nova forma de encarar a realidade (MELO, 2006). 
Marcela Gomez A. da Silva, Evandro Antonio Corrêa,Os Aspectos Limitantes da Formação Acadêmica... Dagmar Aparecida C. F. Hunger

O profissional, de acordo com Corrêa (2009, p. 135), deve-se “[ ...] atentar para as armadilhas da área, ou seja, a formação de meros feitores de atividades, formando "robôs", entendidos como meros executores de atividades". Torna-se, portanto, necessário que os profissionais "[...] tenham a capacidade de transformação, de serem atores sociais com sensibilidade de perceber os limites de cada um e de uma sociedade, de uma cultura, poder enxergar os horizontes, lidar com as incertezas e os conflitos e correr riscos" (CORRÊA, 2004, s.p.).

Por fim, que sejam capazes de questionar a realidade, com uma visão crítica, criativa e significativa, para que estes profissionais possam estar à frente de um trabalho interdisciplinar (CORRÊA, 2009), fato esse que ocorre com os agentes sociais, oriundos de diferentes áreas.

\section{Intervenção Profissional}

Dos agentes sociais entrevistados quatro já atuavam na área mesmo antes da graduação, principalmente os envolvidos com artes, música e teatro, de forma que buscaram a formação acadêmica para aprimorar e adquirir diplomas de cursos acadêmicos como meio de "oficializar seus estudos". Atuavam também em projetos sociais, escolas e aulas em outros locais, como estabelecimentos das Secretarias envolvidas.

$\mathrm{O}$ envolvimento com as atividades do $\mathrm{CEU}$ foi direcionado pelas secretarias envolvidas. As intervenções dos agentes sociais no programa se davam por meio de oficinas que ofereciam o aprendizado de música, artes cênicas e esportes às crianças, jovens e adultos moradores da comunidade e dos bairros próximos ao CEU. 
Marcela Gomez A. da Silva, Evandro Antonio Corrêa,Os Aspectos Limitantes da Formação Acadêmica... Dagmar Aparecida C. F. Hunger

O programa não ofereceu nenhum treinamento para intervir no mesmo, também não havia, até o momento, reuniões com os agentes de todas as secretarias, poucos se conheciam. Não havia uma aproximação entre os agentes das secretarias envolvidas nem com a gestão do programa, conforme relata o agente social 9, "ninguém sabe o que a gente faz aqui”, de forma que essa distância entre os agentes e o programa acabava por interferir na atuação dos mesmos. A falta de interesse por parte da comunidade também tornava as aulas em outros locais mais interessantes, pois se interessavam em sair da comunidade e ir até o centro da cidade para fazer uma aula, por exemplo. Não se interessavam pelo espaço que fora ali construído para que o acesso às atividades fosse facilitado.

Os agentes sociais relataram que há necessidade de ocupação do espaço, no sentido de que a comunidade não entende aquele espaço como "um espaço deles", conforme relatam alguns agentes sociais, após uma semana o local já estava depredado. As pessoas não se interessam muito por atividades no bairro, eles têm interesse em ir ao centro da cidade, fazer as aulas em outros locais e não ali no CEU. "Não há interesse em ir ao curso, ocupar o espaço, eles veem isso como um passatempo" (Agente Social 9).

Sobre os espaços de lazer, Turino (2003) enfatiza que não basta investir na construção de espaços e equipamentos públicos, se não houver uma conscientização da população sobre a importância daquilo em suas vidas.

Uma política pública para o lazer vai muito além da abertura de espaços ou da realização de eventos. É claro que o lazer precisa de ação e espaço para que as pessoas exercitem seu corpo e mente. [...] Mas tão importante quanto os equipamentos públicos está o sentido das coisas, único caminho para a verdadeira emancipação do indivíduo. Sêneca afirmava: "ócio sem estudos é como a morte e a sepultura do homem vivo", por isso a necessidade de desenvolver, de modo concomitante e permanente, um programa de capacitação e convívio social (TURINO, 2003, p. 30-31). 
Marcela Gomez A. da Silva, Evandro Antonio Corrêa,Os Aspectos Limitantes da Formação Acadêmica... Dagmar Aparecida C. F. Hunger

A capacitação profissional é uma busca individual, verifica-se que os agentes foram, conforme relatado eram "jogados lá". Apenas três agentes sociais conheciam os objetivos oficiais do programa, de forma que os demais deduziam alguns deles, relacionando-os, principalmente, à ocupação do tempo, e em "tirar as crianças da rua", por se tratar de um programa de cunho social numa região de vulnerabilidade social, mas não tiveram contato com nenhum material "oficial" sobre o programa.

De acordo com os relatos da entrevista, observou-se um distanciamento entre os agentes sociais e o programa, evidenciado por não conhecerem os objetivos, e por terem sido inseridos naquele local para "preencher horários". Também o distanciamento entre o programa e os sujeitos da comunidade, que mesmo não sendo aqui analisado, acabou por contribuir para o entendimento do desinteresse pelas atividades, limitando a atuação dos agentes sociais.

Todavia, para Corrêa (2009, p.140) o profissional deveria “[...] estar preparado para planejar, administrar, projetar, pensar, mediar, instigar e animar as atividades de lazer, um agente transformador procurando atender as demandas exigidas pela sociedade, bem como propiciar a quebra de possíveis paradigmas de alienação". Assim, os agentes sociais envolvidos no CEU têm a responsabilidade de compreender suas funções e buscar subsídios para sua intervenção, seja na formação continuada, do próprio programa, em documentos, artigos e na própria experiência profissional.

\section{Intervenções e Percepção dos Agentes Sociais: Contexto e Relações Existentes}

Entende-se aqui a palavra contexto como a relação existente entre os sujeitos, o programa e o lazer, e a forma com que se dão as intervenções nesse campo. 
Marcela Gomez A. da Silva, Evandro Antonio Corrêa,Os Aspectos Limitantes da Formação Acadêmica... Dagmar Aparecida C. F. Hunger

\section{Relação Agentes Sociais-Lazer}

Quando questionados sobre o que entendiam por lazer, de maneira pessoal, destacam-se alguns relatos: "Praticar alguma coisa que te faz bem [...] uma coisa que você faz não por obrigação, e sim porque gosta de fazer"- (Agente Social 1); “É aquela atividade que a pessoa vai pra se entreter, pra se divertir"- Agente social 2); "fazer o que a gente gosta, quando a gente se sente bem com uma coisa...é lazer”(Agente social 3); "Lazer é algo que você faz com prazer e que te traga benefícios...físicos, emocionais, estar junto com o outro, isso é lazer”(Agente social 5). "O lazer não é só um tempo livre [...] é uma forma de conhecimento também, desde que explorado de maneira correta [...] ter um tempo de reflexão [...] não o lazer pelo lazer" (Agente Social 7). Para o agente social 9, o lazer está relacionado também ao trabalho, pois "o lazer é aquilo que te tira um pouco do cotidiano e te dá prazer [...] trabalho com o lazer do outro".

Quanto à existência de uma relação entre o lazer e a educação, entre as respostas os agentes sociais responderam que:

"Tudo aquilo que a gente faz ou se propõe a fazer, já traz associado ali alguma aprendizagem, e a pessoa quando tem oportunidade de viver esses momentos de lazer, ele pode incorporar isso na vida dele, fazer com que ele aprenda... as próprias relações sociais (...)As atividades envolvidas no lazer são ricas, então acho que isso principalmente beneficia a bastante a vida adulta..." (Agente Social 6).

O agente social 7 evidencia que "[...] se eximir da responsabilidade de educar, é preparar cidadãos que futuramente não vão ter uma fruição pro lazer... só vão pensar em trabalho, em ganhar dinheiro, materializar [...] não vai ter lazer pra uma pintura, pra uma dança, não vai ter lazer para se expressar de outras maneiras, fica muito preso[...] 
Marcela Gomez A. da Silva, Evandro Antonio Corrêa,Os Aspectos Limitantes da Formação Acadêmica... Dagmar Aparecida C. F. Hunger

se tornando aquela pessoa que falta cultura na vida dela, falta um discernimento sobre o que é arte e o que não é [...] julgamentos rasos[...]”.

O agente social 10 enfatiza que "se não existe a relação entre o lazer e a educação, deve existir o mais rápido possível, porque se vê um desmoronamento do sistema educacional, 'senta ai, fica quieto', passou da hora de incluir e entender de uma forma mais respeitosa com o indivíduo"

Mediante esses relatos, percebe-se uma busca pela valorização da cultura para o lazer. Contudo, apesar do CEU também desenvolver atividades no âmbito do ensino não-formal e da cultura lúdica estar presente, segundo Marcellino (2005), quando vinculado à educação o lúdico pode acabar sendo "instrumentalizado".

Não obstante buscar-se articular o lazer com a educação, observou-se que há uma confusão, por parte dos agentes sociais, em relação ao lazer relacionando as atividades apenas ao "passa tempo" ou entretenimento, pois conforme alguns relatos, as oficinas "são sérias”, “não é só lazer”, "é um lazer sério”. Tendo em vista estes termos percebe-se que há falta de informação e conhecimento por parte dos agentes sociais do potencial educativo do lazer.

Os agentes sociais, por sua vez, deveriam planejar suas intervenções a partir das concepções do lazer, relacionando as atividades com desenvolvimento pessoal, social, de valores, por exemplo. Nesse sentido, os agentes sociais devem compreender que o lazer como veículo e objeto de educação pode contribuir para que indivíduos se tornem mais críticos e criativos, não se tornem alienados pelo modelo social (capital) vigente no país e debatam sobre as possibilidades meramente mercantilista e funcionalista do lazer.

Nesse interim, Marcellino (1987) enfatiza que:

[...] é importante que as atividades de lazer procurem atender as pessoas no seu todo. Mas, para tanto, é necessário que essas mesmas 
Marcela Gomez A. da Silva, Evandro Antonio Corrêa,Os Aspectos Limitantes da Formação Acadêmica... Dagmar Aparecida C. F. Hunger

pessoas conheçam as atividades que satisfaçam os vários interesses, sejam estimuladas a participar e recebam um mínimo de orientação que lhes permita a opção. Em outras palavras, a escolha, a opção em termos de conteúdos, está diretamente ligada ao conhecimento das alternativas que o lazer oferece (MARCELLINO, 1987, p. 122).

Sobre as atividades do programa, se as mesmas se enquadravam no contexto do lazer, responderam de maneira insegura, pois conforme relataram sobre a relação do lazer com a educação, entendiam que relacionar sua aula ao lazer, estariam "perdendo a seriedade" para com o conteúdo a ser trabalhado. "Eu sou contra fazer uma atividade vazia de puro lazer, eu acho que o teatro não é pra isso, ele é um meio de formação" (Agente social 9). Assim o que atribuíam ao contexto do lazer era em relação à maneira como ocorriam algumas atividades das aulas, pois as mesmas eram realizadas por meio de brincadeiras. Na oficina de música, especificamente, um dos agentes sociais responsáveis, relata que por trabalharem na perspectiva histórico- critica $^{3}$, deve-se considerar que a criança, naturalmente, quer brincar: "Uma vez que consideramos a criança como um ser histórico-social, ela gosta de brincar[...] nós procuramos fazer com que nossas atividades sejam prazerosas pra criança” (Agente Social 5).

O Agente Social 9 considera que os cursos oferecidos atuam como "agentes formadores[...] quem realmente tem essa vontade (seguir carreira), que seja um inicio de um caminho e não só um objeto de entretenimento". "Trabalhamos muito em cima de jogos teatrais, consciência corporal, concentração [...] é um trabalho um pouco mais amplo do que um curso de teatro".

Em alguns casos, as intervenções eram elaboradas com base na modalidade específica e com a inserção de brincadeiras que relacionassem o conteúdo proposto, em outros a brincadeira era uma forma de "descanso" da atividade "principal".

\footnotetext{
${ }^{3}$ A pedagogia histórico-crítica propõe o desenvolvimento da prática educativa como um "instrumento potencializador da luta da classe trabalhadora pela transformação estrutural da sociedade atual" (SAVIANI, 2015, p. 130).
} 
Marcela Gomez A. da Silva, Evandro Antonio Corrêa,Os Aspectos Limitantes da Formação Acadêmica... Dagmar Aparecida C. F. Hunger

Também se evidenciou o lazer em atividades compensatórias ou recuperatórias do que se perde durante os momentos de obrigações, sugerindo assim uma sociedade harmônica. Dessa forma, nega-se "a existência de contradições geradas historicamente pelo e no sistema" (PADILHA, 1992, p. 27).

\section{Relação Agentes Sociais-Programa}

As oficinas oferecidas pelo CEU no momento da pesquisa eram: Ginástica para terceira idade, Jogos de Tabuleiro, Boxe, Futsal, Teatro, Grafitti e desenho, Música e Vôlei. Obtive-se 11 entrevistados, totalizando 100\% dos agentes que ministravam oficinas.

A oficina de "jogos de tabuleiro" não havia sido iniciada por falta de interesse da comunidade, assim o agente social 6, responsável por essa oficina, ressalta que o “espaço existia e precisava ser ocupado, mas a comunidade não se interessou, por enquanto". Tal fato se afirma quando o agente social 9 relata que o mesmo ocorre com a oficina de teatro, pois as pessoas se inscrevem, e não aparecem, ou não permanecem, pois possuem uma visão distorcida do que é o teatro, do processo de formação, que é o objetivo proposto por esse curso.

Assim, os agentes sociais 6 e 9 enfatizam que deveria ter sido feito um levantamento sobre o que as pessoas esperavam dos cursos oferecidos pelo programa, assim os agentes sociais e a gestão do programa iriam elaborar estratégias para sanar essas expectativas, a começar por apresentar outras vertentes da encenação que não só a exposta pela mídia em novelas. "[...]é como ir numa comunidade que só come uvas oferecendo maçãs...dizendo que só temos maçãs, vocês vão comer e vão gostar de 
Marcela Gomez A. da Silva, Evandro Antonio Corrêa,Os Aspectos Limitantes da Formação Acadêmica... Dagmar Aparecida C. F. Hunger

maçãs!" (Agente Social 9). Necessita-se de um conhecimento sobre a comunidade e gestão participativa antes de "impor" o que é "melhor" para eles.

Todos consideram o impacto do programa na comunidade de forma positiva, pois contribui para a "ocupação do tempo livre", conforme relatado pelos agentes sociais. E isso é evidenciado diversas vezes, e cria uma visão assistencialista do programa, visão esta que os próprios agentes compartilham.

Melo (2008) já demonstrou em seu artigo sobre "projetos sociais" que a preocupação com a "ocupação do tempo livre", acaba por ser atrelada às "falsas verdades" e à "posturas conservadoras" quando tais locais se propõem à "impedir que crianças se envolvam com drogas", por exemplo. Mesmo sendo uma questão importante, Melo salienta que tal questão "deve estar articulada com sentidos mais amplos que devem ser claramente contemplados nas intencionalidades explícitas nos projetos e programas" (MELO, 2008, p. 14).

\section{Limitações: Dificuldades Encontradas no Programa}

\section{Limitações Encontradas da/para Atuação}

Evidenciam-se aqui as limitações encontradas para atuação conforme relatado pelos agentes sociais:

- A dificuldade em trabalhar num local aberto, como a quadra, por exemplo, em que, muitas vezes contava com a presença de usuários de drogas.

-A indisciplina das crianças, bem como falta de interesse pelas atividades, de forma que já vinham com uma visão pronta sobre as aulas a serem realizadas, criando barreiras para aprendizagem. Os agentes sociais 5 e 9, das oficinas de música e teatro, 
Marcela Gomez A. da Silva, Evandro Antonio Corrêa,Os Aspectos Limitantes da Formação Acadêmica... Dagmar Aparecida C. F. Hunger

respectivamente trabalham na perspectiva de um curso de formação e a comunidade não se interessa da maneira que se espera.

A visão que a comunidade possui sobre o teatro e a música, por exemplo, acabam sendo distorcidas, pois logo querem apresentar uma peça de teatro, tocar um instrumento ou até participar de campeonatos esportivos, enfim, não se interessam pelo processo, apenas pelo produto, fato que ocorre com frequência nas escolas, conforme relata o agente social 9: “eles já querem saber quando vão para o palco, e não é assim [..] mas é a visão que as pessoas tem, na escola fazem isso, teatrinho da escola, teatrinho da igreja, mas aqui estamos falando de formação e é diferente [...].

Constatou-se outro ponto levantado quanto às dificuldades/limitações para atuar com o lazer, especificamente, um agente social evidenciou que os próprios professores têm vergonha de brincar, vergonha do próprio corpo.

Todos os agentes sociais partilhavam da visão de que a comunidade precisa entender o local como um espaço público, com potencialidades educacionais e oportunidades de escolha, e que a gestão do programa deve procurar atender a demanda da comunidade, sem impor as atividades que serão realizadas, pois dessa maneira o interesse seria maior e a adesão às oficinas seria duradoura.

Nesse sentido, Corrêa (2009), apesar de seu estudo estar diretamente relacionado à Educação Física, traz contribuições para o lazer ao pontuar que os profissionais "têm o desafio de compreender as mudanças que ocorrem na sociedade com o passar dos tempos, procurando entender à realidade atual e o que o ser humano faz ou pode fazer no seu 'tempo disponível' em busca a 'felicidade', do prazer, da 'satisfação' (p. 141).

Enfim, como desafio aos agentes sociais, "conquistar" as pessoas para um melhor entendimento sobre os diferentes conteúdos culturais do lazer como os 
Marcela Gomez A. da Silva, Evandro Antonio Corrêa,Os Aspectos Limitantes da Formação Acadêmica... Dagmar Aparecida C. F. Hunger

interesses artísticos, físico-esportivos, sociais etc., promovendo uma participação efetiva da comunidade nas atividades do CEU de forma ativa e, nesse caso, contribuir para uma conscientização de uma educação para o lazer.

\section{Considerações Finais}

Por meio de análise dos relatos dos agentes sociais, evidenciaram-se quatro categorias de análise: formação profissional; intervenção; realidade vivenciada e as limitações encontradas no âmbito do lazer.

Com base nos indícios apresentados pelos agentes sociais que atuam no programa "Centro de Artes e Esportes Unificado (CEU)" e na literatura, entende-se o lazer como campo multidisciplinar, o qual exige uma formação ampliada e continuada. No CEU os agentes sociais são oriundos dos cursos de ensino superior de Letras, Educação Musical, Música, Pedagogia, Artes Visuais, Artes Cênicas e Educação Física (licenciatura e bacharel) e são áreas que podem abordar e oferecer atividades que contemplem os conteúdos do lazer, a fim de proporcionar o desenvolvimento pessoal e social, crítico e criativo.

Entretanto, cabe refletir sobre a maneira que o lazer é abordado e compreendido pelos agentes sociais no CEU. Verificou-se que há uma limitação e conhecimentos superficiais referente ao lazer, contribuindo, talvez, para a disseminação de uma cultura superficial, mercantilizada, ou seja, apenas de consumo. Provavelmente não alcance os objetivos propostos pelo programa CEU, de ordem social e educativa, em que o lazer teria sua parcela de responsabilidade na emancipação cultural e social da comunidade envolvida. 
Marcela Gomez A. da Silva, Evandro Antonio Corrêa,Os Aspectos Limitantes da Formação Acadêmica... Dagmar Aparecida C. F. Hunger

Para que ocorra essa emancipação, um dos caminhos é a formação dos agentes sociais envolvidos no programa sobre os estudos do lazer. Assim como na sua intervenção, e no CEU, que está ligado a uma finalidade socioeducativa, por meio de vivências que envolvam os interesses culturais do lazer e suas potencialidades de desenvolvimento pessoal e social.

Sobre contexto dos agentes sociais constatou-se que suas vivências no campo se limitavam a atividades recreativas durante a graduação (formados em Educação Física), e para os formados em artes, música e teatro, tais vivências se relacionavam ao trabalho que realizavam, de forma que "trabalhavam com o lazer do outro". Também foi constatado que os agentes sociais não relacionavam os conteúdos das oficinas como conteúdos do lazer pelo fato de serem "aulas". Por fim, limitações em trabalhar com a educação para e pelo lazer junto aos grupos de interesse propostos pelo programa devido à falta de conhecimento sobre o lazer.

Surge a necessidade de compreender melhor os programas e projetos desenvolvidos pelas políticas públicas de lazer, para que não se caracterize apenas como assistencialismo. Portanto, os profissionais precisam ser qualificados, necessitam de capacitação por parte dos gestores e/ou programas/projetos para uma atuação que atinja os objetivos propostos.

Isso implica em melhor formação profissional, seja a formação inicial seja a continuada que abordem os estudos do lazer, com intuito de proporcionar a melhoria da qualidade de vida dos indivíduos e a quebra de possíveis paradigmas de alienação da sociedade, por meio de estudos que direcionem uma formação pautada na emancipação dos sujeitos envolvidos, contribuindo para a constituição de sujeitos críticos e criativos (MARCELLINO, 1987; ISAYAMA, 2010; WERNECK, 1998; MELO, 2006). 
Marcela Gomez A. da Silva, Evandro Antonio Corrêa,Os Aspectos Limitantes da Formação Acadêmica... Dagmar Aparecida C. F. Hunger

Por fim, a formação acontece na graduação e num processo continuum, com o intuito de preparar melhor seus profissionais para atuar no campo de trabalho com o desafio de compreender as mudanças que ocorrem na sociedade e ampliar as oportunidades de debate do lazer no currículo dos cursos e que envolvam como, por exemplo, discussões que envolvam políticas públicas de lazer. A partir de sua formação e intervenção sejam capazes de questionar a realidade, com uma visão crítica, criativa e significativa, para que possam estar à frente de um trabalho inter/trans/multidisciplinar e tenham a capacidade de transformação social.

\section{REFERÊNCIAS}

BARDIN, L. Análise de conteúdo. São Paulo: Edições 70, 2011.

BRASIL. Constituição (1988). Constituição da República Federativa do Brasil, 1988. Brasília: Senado Federal, Centro Gráfico, 1988. 292p.

. Ministério da Cultura. Centro de Artes e Esportes Unificados, 2015.

CAMARGO, L. O. O que é lazer. Editora Brasiliense, 1982.

CHIZZOTTI, A. Pesquisa em ciências humanas e sociais. 9. ed. - São Paulo: Cortez, 2008 .

CORRÊA, E. A. Formação acadêmica e intervenção profissional de Educação Física no âmbito lazer. Motriz, Rio Claro, v.15 n.1 p.132-142, jan./mar. 2009.

. Generalidade ou especificidade? Da Cultura Geral a Universidade: qual a Formação do Profissional de Lazer? In: ENCONTRO NACIONAL DE RECREAÇÃO E LAZER, 16, 2004, Salvador. Anais... Salvador, 2004. CD.

CLEMENTE, A. C. F.; STOPPA, E. A. Políticas de lazer dos órgãos públicos de turismo: reflexões sobre uma vivência turística para o morador em sua cidade. Licere, Belo Horizonte, v.18, n.3, set/2015.

DUMAZEDIER, J. Sociologia empírica do lazer. São Paulo: Perspectiva, 1979

. Valores e conteúdos culturais do Lazer. São Paulo: SESC,1980.

FREIRE, P. Educação como Prática da Liberdade. Rio de Janeiro: Paz e Terra, 1989.

GIL, A. C. Métodos e técnicas da pesquisa social. São Paulo: Atlas, 1999. 
Marcela Gomez A. da Silva, Evandro Antonio Corrêa,Os Aspectos Limitantes da Formação Acadêmica... Dagmar Aparecida C. F. Hunger

GOHN, M. da G. Educação não formal e o educador social: atuação no desenvolvimento de projetos sociais. São Paulo: Cortez, 2010.

GOMES, C. Lazer e Formação Profissional: Saberes necessários para qualificar o processo formativo. In: FORTINI, Janice; GOMES, Christianne; ELIZALDE, Rodrigo (Org.). Desafios e Perspectivas da Educação para o Lazer / Desafíos y Perspectivas de la Educación para el Ocio / Challenges and propectes of Education for Leisure. SESC/Otium, Belo Horizonte, 2011, p. 33-46.

ISAYAMA, H. F. O profissional da educação física como intelectual: atuação no âmbito do lazer. In: MARCELLINO, N. C. Formação e desenvolvimento de pessoal em lazer e esporte. São Paulo: Papirus, 2003, p. 59-79.

Papirus, 2010.

(Org.). Lazer em estudo: currículo e formação profissional. Campinas.

LAKATOS, E. M.; MARCONI, M. de A. Técnicas de pesquisa. 7.ed. São Paulo: Atlas, 2008.

LÜDKE, M.; ANDRÉ, M E. D.A. A Pesquisa em Educação: Abordagens Qualitativas. São Paulo: EPU, 1986.

LUNARDI, A. A proteção jurídica do tempo de lazer. In: ISAYAMA, H. F; GOMES, C.L. (Org.). O direito social ao lazer no Brasil. Campinas: Autores Associados, 2015, p. 91-111.

MARCELlinO, N. C. Lazer e Humanização. Campinas: Papirus, 1983.

. Lazer e Educaçãa. Campinas: Papirus, 1987.

. Lazer e esporte: políticas públicas. 2. ed. Campinas: Autores Associados, 2001.

. Pedagogia da animação. 8. ed. Campinas: Papirus, 2005.

. (Org.). Políticas Públicas de Lazer. Campinas: Alínea, 2008.

MATTOS, Mauro Gomes de. Teoria e prática da metodologia da pesquisa em educação física: construindo seu trabalho acadêmico: monografia, artigo científico e projeto de ação. São Paulo: Phorte, 2004

MELO, V. A. A animação cultural: conceitos e propostas. Campinas: Papirus, 2006

“Projetos sociais" de esporte e lazer: Reflexões, inquietações, sugestões; en:

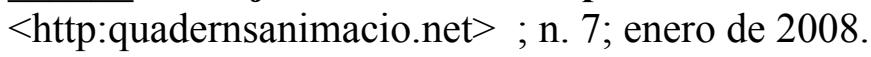

MINAYO, M. C. de S. (Org.). Pesquisa social: teoria, método e criatividade. Petrópolis: Vozes, 1994

NEVES, J. L. Pesquisa qualitativa: características, usos e possibilidades. Caderno de pesquisas em administração - São Paulo, v.1, n. 3, 1996. 
Marcela Gomez A. da Silva, Evandro Antonio Corrêa,Os Aspectos Limitantes da Formação Acadêmica... Dagmar Aparecida C. F. Hunger

PADILHA, V. Trabalho e Lazer: reflexões sobre a abordagem funcionalista. Monografia curso de Especialização em Recreação e Lazer. FEF- Unicamp, 1992.

PINTO, L. M. S. de M. Políticas públicas de lazer no Brasil: uma história a contar. In: MARCELlinO, N. C. (Org.) Políticas públicas de lazer. Campinas: Alínea, 2008.

ROLIM, L. C. Educação e lazer: a aprendizagem permanente. São Paulo: Editora Ática, 1989.

SAVIANI, D. História do tempo e tempo da história: estudos de historiografia e história da educação. Campinas: Autores Associados, 2015.

TURINO, C. (Org.). Lazer nos programas sociais: propostas de combate à violência e à exclusão. São Paulo: Anita, 2003.

WERNECK, C. L. G. Lazer e formação profissional na sociedade atual: repensando os limites, horizontes e os aspectos para a área. Licere. Belo Horizonte. v. 1, p. 47-65, 1998.

\section{Endereço dos Autores:}

Marcela Gomez Alves da Silva

R. Eduardo Vergueiro de lorena, 5-44, apt 112C

Bauru - SP - 17.012-450

Endereço Eletrônico: marcela_gomez@ymail.com

Evandro Antonio Corrêa

Rua Décio Serra, 161 - Maria Isabel

Jaú - SP - 17.215-106

Endereço Eletrônico: prof.evandrocorrea@gmail.com

Dagmar Aparecida Cynthia França Hunger

13 de maio, 7-27, Edifício Bandeirantes, apto A1-12 - Centro

Bauru - SP - 17.015-270

Endereço Eletrônico: dagmar.hunger@fc.unesp.br 